\title{
EDUCAÇÃO, LIBERDADE E DEMOCRACIA: UMA CONEXÃO POSSÍVEL
}

\author{
Genaro Alvarenga Fonseca ${ }^{1}$
}

\begin{abstract}
RESUMO: A consolidação da Educação como prática pedagógica deu origem a escola como instituição, e neste momento tornou-se vulnerável a implantação dos discursos socioculturais dominantes. Em seu campo de atuação a Educação pode oferecer inúmeras possibilidades, no entanto a grande maioria dos educadores não consegue enxergar a escola de forma diferente do que está secularmente estabelecida. A finalidade deste artigo é refletir sobre as possibilidades de se pensar uma escola diferente, onde se privilegie o desenvolvimento da criatividade e da autonomia do pensamento. Nisto estão os princípios de uma "Educação Democrática". O momento atual propicia a troca de pontos de vista e impressões de educadores tanto de visão tradicional como também de vanguarda, desta forma não se pode enxergar a Educação no século XXI que não seja sob a forma de projeto, a Educação tradicional, ao contrário, olha para o passado e isso traz consigo a imobilidade que o novo século, por sua vez não tolera. Sabe-se que os passos da Educação seguem os caminhos direcionados pelos marcos civilizatórios, e as novas perspectivas trazem desafios que fatalmente causam desconforto, contudo, são estes desafios que pretendem transformar a Educação e a lançar neste novo século.
\end{abstract}

Palavras-chave: Educação; Democracia; Escola.

ABSTRACT: The consolidation of Education as a pedagogical practice made possible the school as an institution, whereas education has become vulnerable to the implantation of dominant sociocultural discourses. In its field, the Education is able to offer a large number of possibilities, although most of the educators cannot conceive the school in a different way. The goal of this article is to think the possibilities of a different school, which favors the development of creativity and independence of thought - that is, the basis of a "Democratic Education". In short, this is the favorable moment to take the chance to share experiences and points of view among traditional educators and vanguard educators - we cannot conceive the twenty-first century Education except in a project; contrary to this view, traditional Education tries to look into the past and this conception implies an immobility that the new century does not tolerate anymore. The Education follows the civilizatory paths and the new perspectives bring some uncomfortable challenges - we will point out how these challenges intend to change the Education by inserting it in the new century.

Keywords: Education; Democracy; School.

A Educação, ao longo do tempo foi permeada por diferentes discursos, que the trouxeram normas, regras, direcionamentos, e valores que não faziam parte da sua concepção inicial que seria formar livres pensadores. A consolidação da Educação como prática deu origem à escola como instituição, o que a tornou vulnerável à implantação dos discursos

\footnotetext{
${ }^{1}$ Doutorado em Psicologia pela Universidade de São Paulo (USP). Doutorado em Educação Escolar pela Universidade Estadual Paulista (UNESP) - campus de Araraquara. Professor da Faculdade de Ciências Humanas e Sociais (UNESP - campus de Franca). E-mail: gafonseca@uol.com.br
} 
socioculturais dominantes. A Educação pode oferecer inúmeras possibilidades, no entanto, a grande maioria dos educadores não consegue enxergar a escola de forma diferente daquela que está secularmente estabelecida. O objetivo central deste artigo é refletir sobre as possibilidades de se construir uma escola diferente, onde se privilegie o desenvolvimento da criatividade e da autonomia do pensamento e, inclusive, onde os professores se sintam livres para ensinar o que acreditam.

As experiências efetivas e práticas no campo da Educação Democrática surgiram no início do século XX, mais precisamente em 1921, com as idéias do educador Alexander Neill, que fundou uma escola, na Inglaterra, chamada Summerhill. A trajetória de vida e o questionamento existencial de Neil o levaram a não só repensar a Educação, mas também a estabelecer um novo modelo pedagógico, no qual se desconstruía todo arcabouço do sistema de ensino e aprendizagem e apresentava um padrão absolutamente novo, baseado no interesse dos alunos e alheio aos planos curriculares pré-estabelecidos pelas autoridades educacionais. A proposta de Summerhill não foi levada a sério na época, pois, no início, contava com alguns poucos alunos considerados "problemáticos", o que levava a se pensar, equivocadamente, que a iniciativa tinha pouco a perder e nesse caso, as idéias inovadoras de Neil (1980), consideradas desastrosas, não causariam grande mal. Estas, entretanto partiam do pressuposto de que os alunos aprendiam o que lhes interessavam, e que a aprendizagem deveria levar à satisfação. Neil afirma:

Mantenho que a meta da existência é encontrar a felicidade, o que significa encontrar interesse. A educação deveria ser uma preparação para a vida. Nossa cultura não tem tido grande sucesso. Nossa educação, nossa política, nossa economia, levam à guerra. Nossa medicina não põe fim às moléstias. Nossa religião não aboliu a usura e o roubo. Nosso decantado humanitarismo ainda permite que a opinião pública aprove o esporte bárbaro que é a caça. Os progressos da época são progressos da mecânica em rádio e televisão, em eletrônica e aviões a jato. Ameaçam-nos novas guerras mundiais, pois a consciência social do mundo ainda é primitiva. (NEIL, 1980, p. 22)

As idéias disseminadas em Summerhill foram a princípio tidas como meramente experimentais, mas a longevidade da escola provou o contrário. Seus mais de oitenta anos de história influenciaram de maneira definitiva as concepções de Educação, não por apresentarem um sistema pedagógico próprio, como o Montessori, por exemplo, mas por inserirem de maneira efetiva a questão da liberdade no aprendizado. Sabe-se que não é 
tarefa fácil para o educador abrir mão do direcionamento do ensino, pois este, teoricamente, sabe o que é o melhor para seus alunos. Os críticos de Summerhill, de ontem e de hoje, afirmam que os estudantes não têm maturidade suficiente para decidirem o que devem ou não aprender, contudo, as experiências de Neil demonstraram, pela prática, o contrário. Dizer o que a criança ou o estudante deve fazer ou aprender muitas vezes surte o efeito inverso: a criança tem uma curiosidade intuitiva que pode ser desenvolvida e estimulada, mas nunca direcionada ou reprimida. Neil dá o seguinte exemplo:

Grande parte da desobediência é devida ao método errado de manejar a criança. Zoe, quando tinha pouco mais de um ano, passou por um período em que mostrava grande interesse pelos meus óculos, arrancando-os de meus olhos para ver que tal eram. Eu não protestava, não mostrava aborrecimento no aspecto nem na voz. Depressa ela perdeu o interesse pelos meus óculos e não tocou mais neles. Sem dúvida, se eu tivesse dito, severamente, que não os tirasse - ou pior, se lhe batesse na mãozinha seu interesse pelos óculos poderia ter continuado misturado ao medo quanto a mim. Medo e rebelião. (NEIL, 1980, p. 102)

As crianças e jovens possuem uma natural sinceridade que, com o tempo, vai sendo "moldada" pelas necessidades sociais, morais ou religiosas, ditadas, contudo, por valores impostos que mais cedo ou mais tarde serão alvos de transgressão - isto leva os educadores a questionarem em que momento sua prática foi falha. Neste aspecto, a "pedagogia" de Summerhill conseguiu vencer as barreiras da hipocrisia ao conceder "perigosamente" uma excessiva liberdade a seus alunos, considerando que com ou sem a concessão os jovens tomarão as decisões que julgam as mais acertadas. As idéias pedagógicas tradicionais, por sua vez, redimem os educadores de culpa, pois, em caso de algum resultado adverso, estes possuiriam o álibi de terem avisado, de terem sido contra, enfim de terem se esgueirado da verdadeira tarefa do educador que é apontar todas as vertentes e caminhos que o saber pode conduzir, visto que nem todos os caminhos do conhecimento levam à segurança. Neil ilustra da seguinte forma:

Certa vez levantei-me numa das sessões, e propus que criança alguma com menos de dezesseis anos tivesse permissão de fumar. Argumentei: o fumo é uma droga venenosa, o fumar não correspondia a um verdadeiro desejo da criança, não passava de uma tentativa para parecer adulto. Argumentos contrários foram lançados de todos os lados. Fez-se a votação e fui batido por grande maioria. O que se seguiu vale a pena registrar. Depois da minha derrota, um rapaz de dezesseis anos propôs que nenhuma criança 
com menos de doze anos tivesse permissão para fumar. E defendeu seu ponto de vista de tal forma que chegou a obter aprovação para sua proposta. Entretanto, na assembléia semanal seguinte, um menino de doze anos propôs a anulação da nova regra sobre o fumo, dizendo: - Ficamos todos sentados nos gabinetes sanitários, fumando às escondidas, como fazem os garotos das escolas estritas, e eu acho que isso vai contra o espírito de Summerhill. Sua fala foi aplaudida, e aquela assembléia anulou a lei. Espero ter tornado claro que a minha voz nem sempre é mais poderosa do que a de uma criança. (NEIL, 1980, p. 41)

O exercício da democracia não é de forma alguma uma tarefa fácil, e este é sem dúvida o principal empecilho para que as escolas adotem uma postura mais flexível na condução de suas práticas pedagógicas. Aliás, as escolas pedagógicas, muitas vezes recheadas de metodologias "inovadoras", representam verdadeiros entraves no exercício da democracia. As práticas não podem ser excludentes nem paradoxais, antes, devem se complementar, mas o que ocorre é que cada escola, imbuída de uma visão unitarista, se proclama como sendo a solução final para todos os males da Educação, como afirmam as próprias diretrizes dos PCNs:

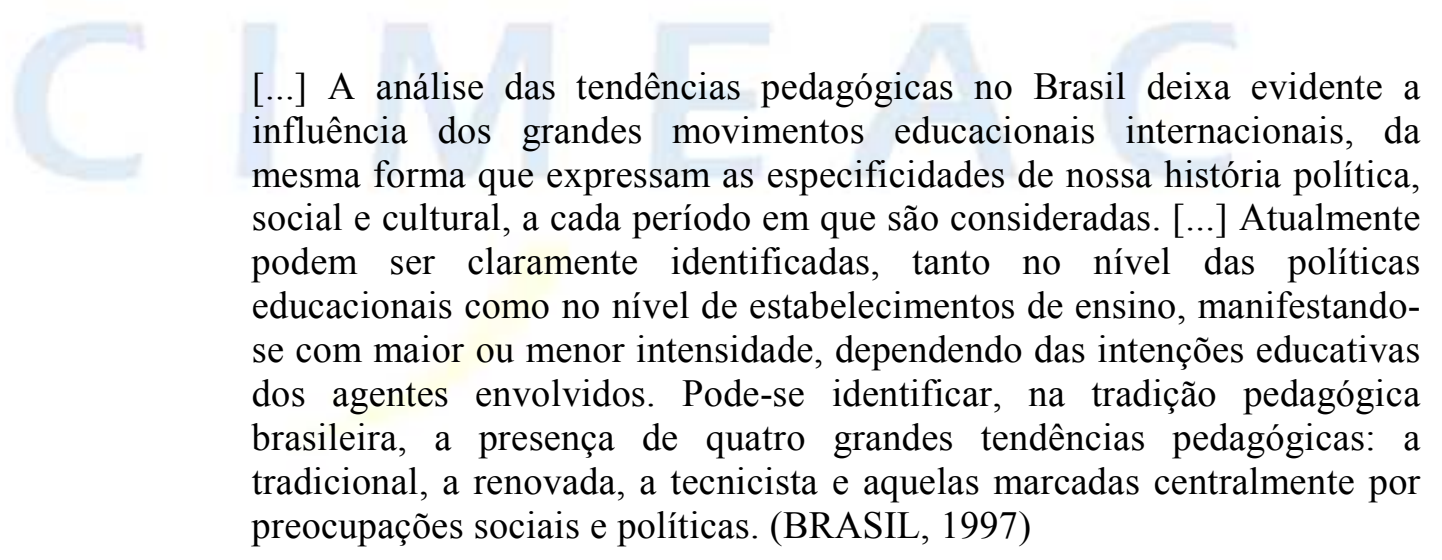

As propostas governamentais evidentemente concordam com as mudanças, apóiam as iniciativas democráticas e, contudo, ainda se prendem em modelos "conteudistas", embora os PCNs afirmem ser sugestões e não disposições:

[...] Os PCNs, pela sua própria natureza, configuram uma proposta aberta e flexível, a ser concretizada nas decisões regionais e locais sobre currículos e sobre programas de transformação da realidade educacional empreendidos pelas autoridades governamentais, pelas escolas e pelos professores. Não configuram, portanto, um modelo curricular homogêneo e impositivo, que se sobreporia à competência político-executiva dos estados e municípios, à diversidade política e cultural das múltiplas 
regiões do país ou à autonomia de professores e equipes pedagógicas. $\mathrm{O}$ conjunto das proposições expressas nos PCNs tem como objetivo estabelecer referenciais a partir dos quais a educação possa atuar, decisivamente, no processo de construção da cidadania, tendo como meta o ideal de uma igualdade crescente entre os cidadãos. Embora, numa sociedade democrática, a igualdade política possa estar assegurada pelas instituições, sabe-se que uma equidade efetiva exige o acesso pleno e indiscriminado dos cidadãos à totalidade dos bens públicos, dentre os quais o conjunto dos conhecimentos socialmente relevantes. (BRASIL, 1997)

Destarte, deve-se observar que a história da Educação brasileira sempre foi marcada por modelos impositores cujas rígidas estruturas curriculares possibilitavam pouca ou nenhuma mobilidade. Esta "velha escola" formou gerações e gerações de educadores que hoje não conseguem pensar de maneira diferente, e assim simplesmente reproduzem as condições educacionais em que foram formados, contrariando, inclusive, o que os PCNs recomendam. A grande inovação da obra de Neil foi justamente que este, em um contexto absolutamente conservador da Inglaterra do começo do século $\mathrm{XX}$, teve a ousadia de propor não apenas uma mudança de método, mas de paradigma ao afirmar que o processo de aprendizagem deveria romper com estruturas curriculares, programas de ensino e até mesmo livros e manuais:

Crianças, como adultos, aprendem o que desejam aprender. Toda outorga de prêmios, notas e exames desvia o desenvolvimento adequado da personalidade. Só pedantes declaram que o aprendizado livresco é educação. Os livros são o material menos importante na escola. Tudo quanto a criança precisa aprender é ler, escrever, contar. $\mathrm{O}$ resto deveria compor-se de ferramentas, argila, esporte, teatro, pintura e liberdade. (NEIL, 1980, p. 23)

Esta idéia de "aprendizagem significativa" viria a ser desenvolvida sistematicamente quase meio século depois pelo educador César Coll (1996), e também prevista nos PCNs:

[...] A aprendizagem significativa implica sempre alguma ousadia: diante do problema posto, o aluno precisa elaborar hipóteses e experimentá-las. Fatores e processos afetivos, motivacionais e relacionais são importantes neste momento. Os conhecimentos gerados na história pessoal e educativa têm um papel determinante na expectativa que o aluno tem da escola, do professor e de si mesmo, nas suas motivações e interesses, em seu autoconceito e sua auto-estima. Assim como os significados construídos pelo aluno estão destinados a serem substituídos por outros no transcurso 
das atividades, as representações que o aluno tem de si e de seu processo de aprendizagem também. É fundamental, portanto, que a intervenção educativa escolar propicie um desenvolvimento em direção à disponibilidade exigida pela aprendizagem significativa. Em síntese, não é a aprendizagem que deve se ajustar ao ensino, mas sim o ensino que deve potencializar a aprendizagem: é o ensino que tem a responsabilidade pelo diálogo com a aprendizagem.

Fica claro que o conceito de Educação Democrática estabelecido por Neil não se baseava em propostas pedagógicas específicas, pois estas traziam novos métodos para se ensinar as mesmas coisas. Summerhill, por sua vez, demonstrou que era possível ensinar coisas novas, que faziam sentido, eram úteis e, por isso, assimiladas. A grande quantidade de informações que as escolas transmitem a seus alunos é simplesmente esquecida na semana subsequente às avaliações; ainda assim, nos dias atuais, as escolas consideradas "fortes" são aquelas que despejam a maior quantidade possível de dados em seus estudantes. É espantoso que já no século XXI ainda se conceba a Educação desta forma, de modo a ser possível observar alunos que no final de seus ciclos educacionais ainda não tenham conseguido transformar informações básicas em conhecimentos. Felizmente as idéias disseminadas por Neil, que foram vistas com certo exotismo na época, não expiraram, como tantas outras tendências inovadoras fugazes do último século. Todavia, as instabilidades do século XX encerraram a criativa década de vinte com uma das piores crises de toda a história, crise esta que só foi rompida com outro evento não menos catastrófico: a II Guerra Mundial. Os anos de guerra envolveram praticamente todo o mundo e exigiram grandes esforços para a sobrevivência; assim, as sociedades agarraram-se a seus valores mais conservadores, na tentativa de encontrar "segurança psicológica" em suas raízes. Desta forma, as mudanças de paradigma só voltaram a ser cogitadas nos anos sessenta. Nos anos que se seguiram ao pós-guerra, a humanidade passou a procurar respostas, pois já ficara evidente que não se podia confiar mais cegamente nas ciências e na política. No final dos anos cinquenta do século XX, desponta uma nova safra de intelectuais denominados geração "Beat" ou "Beatniks", inspirados nas idéias de Jack Kerouac e, no início dos anos sessenta, inicia-se um movimento denominado "contracultura", que difundia a adoção de novos valores culturais, morais e até mesmo estéticos, daí florescem também o movimento hippie e a cultura psicodélica. Os protestos partiram dos jovens, contra todos os tipos de proibição e contra o modo de vida preso a valores morais e religiosos; pregava-se a liberdade de costumes e pensamentos. Nesta época surgiram novas tendências de moda, 
música, expressões e representações, a partir das quais a visão de mundo seria mudada para sempre. Neste período de incertezas e mudanças, as perspectivas existenciais implantadas por Nietzsche voltaram a ser discutidas pelas obras de Sartre, Simone de Beauvoir entre outros, permitindo que novos olhares incidissem sobre velhos problemas, entre os quais a não violência, a liberdade de pensamento, o reconhecimento das diferenças, e a importância dos direitos humanos (especialmente das chamadas minorias, tais como negros, estrangeiros, mulheres, homossexuais etc., que, na perspectiva da sociedade como um todo, representam, na verdade, a maioria). Os jovens estudantes europeus e, posteriormente, os norte-americanos exigiram mudanças; estas vieram primeiramente nas universidades e, em seguida e talvez mais timidamente, em outros setores - contudo, a semente das transformações já fora plantada. A abertura de pensamento dos anos sessenta possibilitou a volta dos olhares para Summerhill, cujas prerrogativas pedagógicas, vistas com novos olhares após mais de quarenta anos de sua fundação, passam a fazer sentido. Várias escolas ditas "alternativas" surgiram nos Estados Unidos e Europa e, posteriormente, em vários lugares do mundo. Algumas escolas, imbuídas do espírito hippie, pregavam não apenas novas propostas pedagógicas, mas também novas formas de vida social - as "sociedades alternativas", a vida em comunidade etc. ${ }^{2}$. Algumas iniciativas não passaram de sonhos utópicos e amadorismo, mas em 1968 foi fundada a Sudbury Valley School, em Framingham, Massachusetts, nos Estados Unidos. Esta escola, de iniciativa particular, abriga atualmente cerca de duzentos estudantes de idades entre quatro e dezenove anos. Sendo uma escola democrática, os únicos princípios básicos são a liberdade de educação e a autogovernabilidade; não existe um currículo a ser seguido nem a seriação de classes. Os alunos de Sudbury Valley aprendem uns com os outros, com os professores, nas conversas, em vivências, enfim, aprendem o que querem aprender. Eles formam espontaneamente seus "grupos de estudos", tal como ocorria nas comunas universitárias da Idade Média. Assim como em Summerhill, os estudantes enviados para Sudbury eram considerados "problemáticos", aliás, as chamadas "escolas alternativas", sejam elas democráticas ou não - no caso, isso não faz diferença - parecem ser as únicas consideradas capazes de resolver problemas de jovens rebeldes, que Alexander Neil chamaria de criativos. O fato é que, a

\footnotetext{
2 Atualmente encontram-se cadastradas 199 escolas democráticas em 30 países, reunidas em: The Online Directory of Democratic Education. Disponível em:

$<$ http://www.democraticeducation.com/schools.htm\#brazil >. Acesso em: 19 nov. 2009. Verificar também: $<$ http://www.educacionalternativa.org $>$. Acesso em: 19 nov. 2009.
} 
partir dos anos oitenta, o modelo empregado em Sudbury Valley espalhou-se de forma vertiginosa pelo mundo, contando atualmente com vinte e seis escolas nos Estados Unidos e onze em outros países. A idéia de não possuir um currículo fixo pode assustar os pedagogos da velha escola, mas atualmente, em um país competitivo como os Estados Unidos, pode parecer uma opção criativa e, inclusive, abrir novas perspectivas ao futuro, principalmente em uma sociedade globalizada. Os princípios da escola são, na verdade, simples, mas expressam os anseios de uma educação voltada para o século XXI, sem os ranços de um "pedagogismo" ultrapassado. Os críticos de Sudbury apresentam os mesmos argumentos que apresentaram outrora contra Summerhill: "se as crianças forem deixadas livres, nada aprenderão". Nada mais falacioso que isso! As crianças e jovens aprendem porque percebem o sentido do que estão aprendendo, obviamente não aprendem tudo, mas apenas aquilo que se interessam. Pode-se ainda refutar: "a vida em sociedade exige que se aprenda muito além do que se quer aprender". Ora neste aspecto, é preciso romper as barreiras da hipocrisia e refletir se na escola tradicional os alunos aprendem pelo menos uma parte do que lhes é ensinado. Os princípios de Sudbury são bastante simples:

1. As pessoas são curiosas por natureza.

2. As pessoas aprendem facilmente quando elas mesmas tomam a iniciativa da aprendizagem.

3. As pessoas que são deixadas em paz tornam-se criativas e desenvolvem os seus talentos.

4. Pela miscelânea de idades desenvolvem-se todos os membros do grupo. 5. A liberdade é essencial para a tomada de responsabilidade individual.

Desta forma os alunos realmente aprendem - vale lembrar que não se está discutindo, neste momento, a quantidade de informações, mas o conhecimento efetivamente adquirido. Singer (1997, p. 159), na época de sua pesquisa, traz os seguintes dados sobre os egressos de Sudbury Vallley: 75,4\% deles continuaram seus estudos; quanto ao restante, 24,6\% não continuou os estudos pelo fato de achar desnecessário. Dedicaram-se a negócios de família, às artes ou tornaram-se empresários. Além de Summerhill e Sudbury, que são escolas particulares, destinadas a jovens da classe média, pode-se trazer à discussão outro modelo de escola bem menos provida de recursos, mantida pelo estado e destinada a alunos das classes trabalhadoras, que é o caso da Escola da Ponte. O exemplo desta escola já se tornou notoriamente conhecido quando se fala de implantação de ideais democráticos, contando com as condições e as estruturas limitadas de uma escola pública. Quando o 
professor José Pacheco assumiu a direção da escola, não contava com quase nada além de sua vontade de promover mudanças que pudessem auxiliar da melhor maneira possível sua clientela carente. Em recente entrevista, Pacheco afirmou:

Em 1976, a Escola da Ponte era um arquipélago de solidões. Os professores remetiam-se para o isolamento físico e psicológico, em espaços e tempos justapostos. Entregues a si próprios, encerrados no refúgio da sua sala, a sós com os seus alunos, o seu método, os seus manuais, a sua falsa competência multidisciplinar, em horários diferentes dos de outros professores, como poderiam partilhar, comunicar, desenvolver um projecto comum? O trabalho escolar era exclusivamente centrado no professor, enformado por manuais iguais para todos, repetição de lições, passividade. As crianças que chegavam à escola com uma cultura diferente da que aí prevalecia eram desfavorecidas pelo não reconhecimento da sua experiência sociocultural. Algumas das crianças que acolhíamos transferiam para a vida escolar os problemas sociais dos bairros pobres onde viviam. Exigiam de nós uma atitude de grande atenção e investimento no domínio afectivo e emocional. Há vinte e cinco anos, tomámos também consciência de novas e maiores dificuldades. Por exemplo, de que não passa de um grave equívoco a ideia de que se poderá construir uma sociedade de indivíduos personalizados, participantes e democráticos enquanto a escolaridade for concebida como um mero adestramento cognitivo. (CASIMIRO, 2000)

A Escola da Ponte, no início, também acolheu estudantes ditos problemáticos, não por força de sua "metodologia alternativa", mas por estes fazerem parte de um contingente de excluídos. A lógica perversa da educação tradicional sempre valorizou os alunos que nunca criticam o sistema, e pelo contrário, estudam passivamente, reconhecem o próprio fracasso e, quando este se torna recorrente, fazem o que é esperado: abandonam a escola. $\mathrm{O}$ desafio de Pacheco estava lançado: ou dirigiria a escola nos moldes convencionais, aceitando o inevitável malogro de seus alunos frente à vida, ou tentaria algo novo, muito além dos estratagemas pedagógicos ministrados pela estrutura governamental. O início da Escola da Ponte, tal como se conhece, foi bastante complicado. O diretor deveria proceder conforme reza a legislação, contudo, Pacheco foi além, muito além: literalmente derrubou as paredes que traziam as diferenças sociais, culturais e excludentes à tona. Por outro lado, também expôs as dificuldades com o fato de ter que lidar com situações novas, deixando de lado a face confortável da apatia. Pacheco rememora estes tempos:

É uma escola muito engraçada, não tem salas de aula, não tem turmas divididas por faixa etária, não tem testes, não tem nada. Nada da escola 
tradicional que conhecemos. É uma escola feita com muito esmero em Vila das Aves, Portugal. Na Escola da Ponte, as crianças decidem o que e com quem estudar. Em vez de classes, grupos de estudo. Independente da idade, o que as une é a vontade de estar juntas e de juntas aprender. Novos grupos surgem a cada projeto ou tema de estudo. Quem ouve falar dela pela primeira vez hesita em acreditar. Surpresa maior só mesmo de quem a conheceu nos anos 70. A Escola da Ponte era uma escola muito engraçada, não tinha bancos, não tinha mesas, não tinha nada. $O$ banheiro sequer porta tinha. "Satisfazer as necessidades biológicas mais elementares constituía um teste de entreajuda: as alunas iam lá fora em grupos de cinco, ou seis, fazia-se a parede e a porta num círculo humano em torno da necessitada". Hoje, os alunos têm um espaço para publicar pequenos anúncios de oferta e procura de ajuda para realização de pesquisas escolares, reúnem-se semanalmente em assembléia para debater os problemas da escola e redigem seus direitos e deveres. (CASIMIRO, 2000)

O grande contra censo que ocorreu foi que, pelo fato de ser uma escola quase esquecida, as inovações passaram desapercebidas das autoridades. Aliado a este fator, podese chegar ao desaforado raciocínio: com as inusitadas mudanças, o que tinham a perder os alunos da antiga Escola da Ponte? Já não estavam perdidos? Esta lógica perversa pode perpassar a consciência de quem pensa em inovar no campo da Educação, mas teme pelos resultados. Aliás, se o sistema educacional vigente que se pauta por resultados realizasse uma conexão de dados mais eficiente, veria claramente que se tornou um aparelho ineficiente, retrógrado e, sobretudo dispendioso. A escola da Ponte, sob a gestão de Pacheco, tornou-se em poucos anos um centro mundial de referência de ensino, isso sem despender nenhuma verba extra. A escola passou aproximadamente uma década despercebida das preocupações das autoridades educacionais, que só voltaram os olhos à Ponte quando seus alunos começaram a se destacar de forma surpreendente nos exames nacionais. Qual não foi a surpresa dos dirigentes de ensino quando se depararam com uma realidade totalmente inusitada! Neste momento, iniciou-se uma verdadeira sindicância inquisitorial que terminou somente em 1997, quando, em reconhecimento à sua excelência, a Escola da Ponte adquiriu junto ao Ministério da Educação de Portugal maior autonomia, o lhe permitiu realizar a contratação de professores e mesmo a oficialização de seu sistema curricular. Infelizmente o exemplo da Ponte não foi seguido de imediato por outras escolas, aliás, passou praticamente ao largo do resto do mundo. A escola se popularizou no Brasil graças aos relatos apaixonados de Rubem Alves (2005) quando a esteve visitando, em 2000: 
Conto essas coisas da minha vida de menino para dizer que as crianças são curiosas naturalmente e têm o desejo de aprender. O seu interesse natural desaparece quando, nas escolas, a sua curiosidade é sufocada pelos programas impostos pela burocracia governamental. Pela minha vida tenho estado à procura da escola que daria asas à curiosidade do menino que fui. Pois, de repente, sem que eu esperasse, eu me encontrei com a escola dos meus sonhos. E me apaixonei.

Ao retornar de Portugal, o educador trouxe na bagagem suas experiências na Escola da Ponte, e isto fez com que se voltassem as atenções para as iniciativas de José Pacheco. O que é digno de nota é que foi necessária a disseminação de relatos românticos de um escritor carismático para se travar conhecimento com uma proposta pedagógica tão simples e, ao mesmo tempo, tão séria. É também pertinente ressaltar que a Escola não se pautou por uma corrente pedagógica inovadora redigida por um núcleo de intelectuais de vanguarda, mas residiu na simplicidade de um educador que almejava ajudar seus alunos da melhor maneira possível, com os parcos recursos que possuía. O que basicamente diferencia a escola é que esta realmente exercia o que se propunha a realizar. Os planos e projetos pedagógicos previstos nas LDBs são, de forma geral, muito bem elaborados, possuem propostas inovadoras e todos privilegiam a qualidade de ensino. Contudo, o que se vê na prática é uma completa descontinuidade: os dirigentes de ensino recebem as propostas pedagógicas, enviam às escolas, os diretores repassam aos professores e estes "se viram" para transmitirem-na aos alunos. O que acontece, na verdade, é que nada muda. A sala de aula na escola pública é hoje praticamente o que era há quarenta anos ou mais! Diferentemente do que é feito por meio das ações governamentais, a Ponte parte da realidade do aluno para depois desenvolver suas práticas pedagógicas. Pacheco (2003) afirma o seguinte:

A organização do trabalho na escola gravitará em torno do aluno, devendo estar sempre presente no desenvolvimento das actividades a ideia de que se impõe ajudar cada educando a alicerçar o seu próprio projecto de vida. Só assim a escola poderá contribuir para que cada aluno aprenda a estar, a ser, a conhecer e a agir. A dimensão do estar será sempre garantida pela integração do aluno na comunidade escolar onde conhece e é conhecido por todos os pares, orientadores e demais agentes educativos. Os alunos e os orientadores educativos deverão contratualizar as estratégias necessárias ao desenvolvimento do trabalho em planos de periodicidade conveniente, assim como ser co-responsáveis pela avaliação do trabalho realizado. 
Nada funcionaria se não houvesse verdadeiramente o comprometimento com o projeto de cada professor, de cada aluno, do diretor e dos pais. O que acontece frequentemente, nas escolas tradicionais - sendo inclusive uma prática aceita -, é a sórdida divisão de poderes: cada qual opera modicamente sob sua estrita faixa de atuação, não há conexão alguma entre alunos, professores e direção. E, assim, a escola se perde na sua função primordial, que é propiciar um ambiente de estudo e aprendizagem entre educadores e educandos. Se analisada de maneira estrita, a Escola da Ponte não apresenta nada de revolucionário nem maravilhoso, apenas cumpre a fazer o que se propõe. A fórmula parece bem simples e eficiente: todos têm consciência do que estão fazendo, sem que se precise de uma rígida estrutura hierárquica para designar funções, inclusive a função de aprender. Outra grande preocupação das escolas tradicionais é a questão do currículo: imagina-se, comumente, que uma boa escola deva possuir um excelente currículo, inovador, dinâmico e capaz de atender às exigências de seu tempo. Na Ponte esta preocupação passa de certa forma despercebida, pois o que move o interesse dos alunos é sua curiosidade e disposição para aprender e não uma matriz curricular imposta. Isto pode ser de grande ajuda para o desenvolvimento do processo de ensino e aprendizagem, visto que os alunos aprendem porque querem aprender; nisso consiste o processo de aquisição de conhecimento e não apenas numa inútil coleta de informações para serem utilizadas em processos de avaliação e em seguida esquecidas. Na Escola da Ponte tem-se a preocupação de que o conhecimento chegue ao aluno e que aquele possa ser útil e aplicável; assim, cada estudante representa uma particularidade com disposição própria para absorver esta ou aquela informação, mas, sobretudo tem a capacidade de perceber que o conhecimento está à sua disposição no dia a dia, que pode ser apreendido e utilizado. Assim, a formalidade curricular torna-se desnecessária, uma vez que os alunos naturalmente procurarão informações e, a partir daí, transformá-las-ão em conhecimentos que realmente façam sentido. A grande preocupação dos defensores das pedagogias ditas tradicionais, e mesmo de "entusiastas conservadores", é o medo de errar, de não dar certo, do desconforto da novidade - nisto se apóia a cruel inércia do conformismo. Não se precisaria discutir o presente tema se há décadas algumas medidas simples como as tomadas por José Pacheco tivessem sido levadas a cabo. Gerações de educadores esperam a salvação a cada nova LDB e a situação tende a piorar cada vez mais. No caso do Brasil, os alunos aprendem cada vez menos, independentemente dos recursos que são aplicados no setor educacional. A questão do aprendizado em si deveria ser 
o ponto central de todas as discussões que envolvem a Educação: a escola deve ensinar da maneira tal que seu aluno aprenda. Evidentemente, assim não se pode falar de uma estrutura curricular uniforme, aliás, nem a própria LDB a determina - o que ocorre é que a liberdade de ensino dentro da escola esbarra na sombra de um arcabouço burocrático arcaico. Neste contexto, alguns educadores retrógrados ainda pensam que podem controlar a situação apoiados em uma estrutura legalista. Inevitavelmente chega-se à seguinte conclusão: se o que importa para o aluno é o conhecimento, por que não possibilitar que este o adquira de forma democrática, conforme suas particularidades e necessidades? Os currículos oficiais estão muitas vezes tão distantes da realidade que muitos professores sequer vêem sentido em transmiti-los. Assim, fatalmente, em sua grande maioria os programas das disciplinas da rede pública, e também da privada, deixam de ser vistos ou são cumpridos de forma inadequada. O resultado não poderia ser diferente: a falta de aprendizado em todas as instâncias. O próprio sistema reconhece suas faltas e não só as aceita, mas também estabelece medidas emergentes paliativas, como os cursinhos preparatórios para os exames vestibulares. O cursinho pré-vestibular surgiu para ajustar uma falha intrínseca ao sistema, que é tentar complementar informações necessárias para os exames vestibulares que não foram transmitidas no Ensino Médio. Neste quadro, os cursinhos pré-vestibulares tornaramse praticamente um "componente curricular", um apêndice sem o qual os alunos sentem-se incapazes e incompletos para prosseguirem os estudos. Na verdade, os cursinhos não são outra coisa que uma verdadeira torrente de informações lançadas sobre os estudantes para serem memorizadas, sem qualquer sentido que não seja o vestibular. O fenômeno do cursinho surge já na década de cinquenta, quando a procura excedia a oferta no número de vagas nas universidades. O negócio se tornou inclusive lucrativo e bastante lucrativo, e a partir daí surgiram inúmeras "escolas" oferecendo esta modalidade de "ensino". Diante da impotência ante a situação, alguns estudantes da Faculdade de Filosofia da Universidade de São Paulo criaram, em 1962, o primeiro cursinho popular do Brasil, com a finalidade de proporcionar a jovens carentes igualdade de condições para os exames vestibulares. A partir da década de setenta até os dias atuais, vem aparecendo uma grande quantidade destes cursos, geralmente ligados a universidades públicas. Neste sentido, os cursinhos comunitários ou populares representam uma tentativa, aliás, bastante eficiente, da sociedade civil com a finalidade de "corrigir" as distorções, ou melhor, as deficiências do sistema escolar vigente. O objetivo primordial dos cursinhos populares, além de democratizar o 
acesso dos alunos à universidade, é contribuir para seu processo de construção da identidade; para tanto é necessário que estes desenvolvam uma visão abrangente e crítica da realidade. Sabe-se que esta modalidade de ensino é basicamente emergencial e em nada melhora a qualidade da educação, contudo, pode proporcionar aos jovens estudantes das escolas públicas, que, no caso, representam as maiores "vítimas" do sistema de ensino defasado, uma oportunidade de adentrar a universidade. O ideal de todo cursinho popular é oferecer também noções de cidadania e conscientização, assim sendo, almejam que seus estudantes egressos tornem-se também militantes de causas sociais. A tarefa não é simples, pois a maior parte dos estudantes que procuram os cursinhos populares traz do Ensino Médio uma grande defasagem e isso deve ser corrigido em menos de um ano. Por defasagem entende-se falta de informações; se for considerado o item conhecimento, a situação mostra-se pior ainda. A tudo isso se pode adicionar o fato dos cursinhos populares terem a preocupação de fornecer também uma formação crítica da realidade social, de construir noções de cidadania e permitir que os estudantes enxerguem a própria identidade, mascarada pelo sistema opressor em que vivem. As questões que envolvem o ensino e a aprendizagem são, na verdade, a mola mestra de todas as inquietudes e reflexões. Sob este aspecto, o educador espanhol César Coll (1996) tem apontado caminhos alternativos que buscam um sentido mais aprofundado para as práticas pedagógicas, levando à reflexão sobre metodologias e práticas desenvolvidas no cotidiano escolar. Estes caminhos, embora não sejam de todo novos calcam-se, por exemplo, em reflexões já debatidas por Vigotsky e Piaget - visam a operacionalização destas idéias e sua aplicação prática na realidade escolar.

Os caminhos apontados por Coll (1996) indicam a importância da aprendizagem significativa como meio de despertar a curiosidade e mesmo a atenção dos alunos para a importância real da educação em suas vidas. A legislação educacional brasileira não está alheia a estes questionamentos, aliás, a nova LDB 9394/96 prevê que o aprendizado deve ir ao encontro das aspirações do aluno, aproveitando seus conhecimentos prévios e respeitando suas diversidades culturais. Não obstante estas prerrogativas bastante coerentes é possível deparar-se com o já comentado quadro de estagnação e com as incongruências das práticas pedagógicas presentes nas escolas. Sabe-se que a evasão escolar diminuiu nos últimos anos, porém esta perspectiva quantitativa não é de modo algum proporcional a uma melhor qualidade de ensino; os alunos egressos do Ensino Médio não estão aptos a serem aprovados 
em exames vestibulares para acesso a universidades públicas, tampouco preparados para o mercado de trabalho e sequer conscientes de sua própria cidadania.

Cabe neste espaço esmiuçar as atividades do "cursinho" popular Conexão que pode ser usado como exemplo de um espaço não formal de educação, mas altamente comprometido com o processo de ensino e aprendizagem sob uma perspectiva crítica e voltada a autonimia. O “Conexão" trata-se de um curso gratuito, na cidade de Ribeirão Preto, formado inicialmente por um grupo de graduandos da USP, os quais fundaram em 2002 a ONG CIMEAC ${ }^{3}$, com o objetivo de democratizar o conhecimento escolar e universitário por meio do desenvolvimento e investigação de metodologias educacionais alternativas. A idéia central que motivou os jovens professores, muitos inclusive sem grande experiência docente, a unirem esforços ao fundarem o cursinho foi o vislumbre da construção de um sistema pedagógico inovador e democrático, e fundamentalmente prático, visto que o cursinho em si funcionava como um verdadeiro laboratório de práticas pedagógicas. O "Conexão" conta atualmente com onze professores e vários alunos colaboradores, as aulas são geralmente coordenadas por dois ou mais professores ao mesmo tempo; estes apresentam o tema e os alunos aprofundam suas pesquisas em grupo. Aos sábados são realizadas reuniões pedagógicas onde todos participam, é feito um relatório e avaliação da semana anterior e comumente se discute algum tema de interesse comum geralmente associado a questão de construção de identidade ou cidadania, para isso os alunos lêem textos curtos de Perrenoud, Bourdieu, Morin, Gramsci, etc. e debatem junto com os professores e alunos colaboradores que já estão na Universidade. Desta forma os alunos do curso "Conexão" conseguem visualizar na prática a importância do conhecimento. Verificou-se ao longo desta análise que grande parte dos alunos que deixam do Ensino Médio não fazem idéia de seu propósito.

Neste momento, o papel destes cursinhos populares revela-se fundamental no sentido de "amparar" estes alunos fornecendo-lhes esperança e elevando-lhes a auto-estima, pois o "público-alvo" dos cursinhos populares não possui condições financeiras para arcar com as despesas de outros cursos particulares ou faculdades privadas. A metodologia de ensino, bem como os direcionamentos pedagógicos empregados no "Conexão" expressam os princípios da Educação Democrática onde a transdisciplinaridade, funciona como uma "ferramenta" essencial para que os estudantes possam compreender melhor sua realidade e assim estabelecerem seus próprios princípios de identidade e cidadania. Dentro de suas disposições

\footnotetext{
${ }^{3}$ Centro de Investigações de Metodologias Educacionais Alternativas Conexão.
} 
pedagógicas os conteúdos curriculares são interligados com o intuito de demonstrar a continuidade e a coesão dos conhecimentos, tanto do ponto de vista científico quanto prático; assim as disciplinas "fundem-se" sob a forma de questionamentos e problemas a serem visualizados e resolvidos pelos alunos. A idéia central do "Conexão" é estabelecer uma profunda interligação de informações e dar suporte para que os próprios alunos transformem as informações que recebem em conhecimento. A função dos professores não é dar aulas no sentido tradicional, mas fazer com que os alunos consigam atrelar os conhecimentos que eles já possuem com informações novas, rompendo as barreiras disciplinares e produzindo o próprio conhecimento dentro de suas necessidades e prioridades. Para isso, os estudantes reúnem-se em grupos e trocam informações, saberes e vivências; os professores agem apenas como facilitadores, visando que os alunos desenvolvam sua autonomia. Isso pode ser confirmado pelo fato de que nenhum dos estudantes entrevistados citou a participação dos professores em seu processo de aquisição de conhecimentos. O grupo "Conexão" não possui um sistema hierarquizado de direção e poder, todos tomam decisões em conjunto. Até mesmo nas aulas existe bastante autonomia visto que os alunos organizam seus grupos de estudo e os professores entram em cena só em casos de dúvidas ou para organizarem as exposições dos conteúdos apreendidos. Sabe-se que a atuação dos docentes é fundamental, mas esta não pode ser vista como a única via de acesso dos alunos ao conhecimento. Embora este método possa parecer inovador, o mesmo já havia sido preconizado por Piaget (1970), sob a perspectiva do construtivismo. O conteúdo a ser desenvolvido nas aulas é dividido em módulos, com entrelaçamento de tópicos das diferentes matérias, mas visando abordar a estrutura curricular básica prevista para o Ensino Médio. Os módulos a serem desenvolvidos durante no decorrer do ano letivo basicamente são: Água, Transporte, Ciência Tecnologia, Energia, Esporte, Direitos Humanos, Economia, Arte e Cultura, podendo variar ano a ano, sua elaboração conta inclusive com a participação dos alunos, onde estes inclusive inserem assuntos de seu interesse. Os módulos consistem em temas centrais envolvendo diversos assuntos a serem discutidos em uma perspectiva multidisciplinar; geralmente os alunos se reúnem em grupos e procuram buscar soluções para um problema proposto de acordo com o tema do módulo. $\mathrm{Na}$ busca de soluções os alunos percorrem diversas áreas de conhecimento trocando informações e experiências, além de exercitarem uma convivência humana sob diversos aspectos, criando laços afetivos, divergência de opiniões, atritos e, sobretudo, desenvolvendo sua identidade individual e coletiva. O objetivo primordial da repartição dos conteúdos em módulos é fazer 
que os alunos possam perceber, usando seus próprios recursos, as possibilidades de interrelações que o conhecimento proporciona, visando não apenas transmitir conhecimentos, mas também demonstrar as possibilidades de interligação de saberes de diferentes áreas. Para isso são necessários esforços constantes, estudos e reuniões pedagógicas, além da disponibilidade dos professores para estarem constantemente revendo suas práticas. Não obstante o fato de vislumbrarem a possibilidade e adentrarem a universidade, a interdisciplinaridade é fundamental para que desenvolvam um senso de cidadania, construam sua identidade e assim compreendam sua real participação na vida social. No curso "Conexão" a preocupação central não é o vestibular em si, mas fazer com que os estudantes desenvolvam um senso crítico de sua própria realidade. Nesta perspectiva, os cursinhos populares visam, sobretudo, promover a inclusão de estudantes que são automaticamente conduzidos a um processo de exclusão. Sabese que não existem vagas para todos na universidade pública, aliás, esta desde sua criação, nunca foi concebida para abrigar a todos, ainda mais estudantes advindos das classes trabalhadoras; assim, os cursinhos populares funcionam como verdadeiros movimentos de militância e resistência. Cada aluno levado à universidade pública representa uma enorme vitória contra as adversidades que a própria sociedade lhe impôs. Muito se discute sobre as perspectivas futuras da escola, de ontem e de hoje; foram feitos planos, legislações e projetos, no entanto, pouco mudou. É uma insensatez fechar os olhos para o descaso em que se encontram alguns setores da educação pública. A atual conjuntura apresenta um quadro calamitoso no que diz respeito ao que os estudantes egressos do Ensino Médio realmente sabem: a verdade é que grande parte dos jovens aprendem muito pouco ou quase nada. Pode-se fazer um questionamento empírico e refletir quantos estudantes saídos da escola pública sabem definir o que são números complexos, fazer um cálculo estequiométrico, explicar a Revolução Francesa, ou mesmo localizar o Haiti no mapa. Estas informações, que fazem parte da grade curricular e são exigidas em exames vestibulares, em geral não fazem sentido para os alunos, portanto, não despertam o menor interesse. Mesmo assim, as escolas insistem em transmitir estas mesmas informações da mesma forma há décadas. $O$ resultado não poderia ser diferente do que se pode observar aleatoriamente nas escolas da rede pública. Não se pode pensar, no entanto, que esse conhecimento não seja importante ou que a escola deva sonegar informações. Não é isso. O que deveria mudar urgentemente é a forma de abordar estes temas, o modo com que as informações deveriam ser dirigidas, para que possam se transformar em conhecimentos que tenham sentido e sejam úteis. O conjunto 
de informações transmitido pelos conteúdos curriculares não deve ser deixado de lado, pelo contrário, é extremamente importante, mas somente quando o aluno percebe que isto está relacionado com seu mundo. Estudar, por exemplo, a Revolução Francesa a partir de fatos, datas e nomes é completamente inútil e sem sentido, mas refletir sobre as condições sociais e econômicas às quais os próprios alunos estão expostos é interessante e importante; estudar maneiras e possibilidades de mudança na sociedade, no meio que se vive é interessante e importante; pensar como estas mudanças poderão ocorrer também é uma questão de relevância, e isso é facilmente reconhecido pelos alunos. Neste contexto, o estudo da conjuntura histórica da Revolução Francesa passa a fazer sentido pelo fato de que, a partir daí, o aluno pode enxergar uma situação real que ocorreu. Ou seja, o estudo da História, precisa mostrar a concretização de ações que ocorreram a partir de pensamentos e anseios. O mesmo deve ocorrer com as outras disciplinas - aliás, o ideal seria que não houvesse a compartimentação rígida do currículo em disciplinas, mas que os alunos percebessem que tudo faz parte do âmbito do conhecimento. Desta maneira, não se pode enxergar uma Educação no século XXI que não seja sob a forma de projeto. Quando se lança algo à frente, o que se pode fazer é acompanhar sua trajetória, olhando para o que foi lançado e caminhar na sua direção. A Educação tradicional, ao contrário, olha para o passado e isso traz consigo uma imobilidade que o novo século, por sua vez, não tolera. Os passos da Educação seguem os caminhos direcionados pelos marcos civilizatórios; a escola atualmente ainda segue a ideologia do desempenho e da eficiência da Educação burguesa. Os novos caminhos da Educação trazem desafios e estes causam desconforto, contudo, parte deste caminho já foi trilhada, conforme as experiências citadas ao longo deste trabalho. O grande projeto educacional para o século XXI talvez seja construído no dia a dia, sem a segurança confortável de saber que tudo já está pronto e todas as questões já estão respondidas, mas com a certeza de estar construindo um caminho seguro para a emancipação.

\section{REFERÊNCIAS BIBLIOGRÁFICAS}

BRASIL. Secretaria da Educação Fundamental (1998). Parâmetros Curriculares Nacionais: Terceiro e Quartos Ciclos: Apresentação dos Temas Transversais/ Secretaria de Ensino Fundamental/ Brasília: MEC/SEF. 
COLL, Cesar; PALÀCIOS, Jesus; MARCHESI, Álvaro (orgs). Desenvolvimento Psicológico e Educação. Porto Alegre: Artes Médicas, 1996. 2 V.

. Psicologia do Ensino. Porto Alegre: Artes Médicas, 2000.

FREIRE, Paulo. A educação como prática da liberdade. Rio de Janeiro: Paz e Terra, 1967.

GADOTTI, Moacir. Pensamento Pedagógico Brasileiro. São Paulo: Ática, 1995. 2000 . Perspectivas atuais da educação. São Paulo em Perspectiva, São Paulo, v. 14, n. 2 ,

NEILL, Alexander Sutherland. Liberdade sem excesso. Trad. Nair Lacerda. São Paulo: Ibrasa, 1982.

Liberdade sem medo (Summerhill). Pref. Erich Fromm. Trad. Nair Lacerda. São Paulo: Ibrasa, 1980.

PIAGET, Jean. Psicologia e Pedagogia. São Paulo: Forense, 1970.

SAVIANI, Dermeval. História das idéias pedagógicas no Brasil. Campinas: Autores Associados, 2007.

\section{Fontes eletrônicas}

ALVES, Rubem. A escola dos meus sonhos. Educação, São Paulo, 2005. Disponível em: $<$ http://www.feg.unesp.br/ $\sim$ saad/educacao/Rubem alves escola da ponte.doc $>$. Acesso em: 08 nov. 2009.

BRASIL. Parâmetros Curriculares Nacionais. Disponível em:

$<$ http://www.zinder.com.br/legislacao/pen-fund.htm>. Acesso em: 10 jan. 2009.

BRASIL. Plano Nacional de Educação. Disponível em:

$<$ http://portal.mec.gov.br/arquivos/pdf/pne.pdf $>$. Acesso em: 08 dez. 2009.

CASIMIRO, Vitor. Entrevista com José Pacheco: escola dos sonhos existe há 25 anos em Portugal. Portal Educacional, nov. 2000. Disponível em:

http://www.educacional.com.br/entrevistas/entrevista0043.asp. Acesso em: 24 out. 2009.

PACHECO, José. Fazer a Ponte: projecto educativo. Vila das Aves: EBI Alvez/São Tomé de Negrelos, 2003. Disponível em: $<$ http://tandis.odihr.pl/documents/hrecompendium/CD $\% 20$ SEC $\% 202 \% 20$ ENV/Make $\% 20$ the $\% 20$ bridge/Make $\% 20$ the $\% 20$ Bridge $\%$ 20Portugal\%20Attach\%201\%20PORT.pdf >. Acesso em: 13 jun. 2010.

THE ONLINE DIRECTORY OF DEMOCRATIC EDUCATION. Disponível em: $<$ http://www.democraticeducation.com/schools.htm\#brazil $>$. Acesso em: 19 nov. 2009. 